\title{
Endoscopic sinus surgery training courses: benefit and problems - a multicentre evaluation to systematically improve surgical training*
}

\author{
Thomas Braun ${ }^{1, \S}$, Christian S. Betz ${ }^{1, \S}$, Georg J. Ledderose', Miriam Havel', \\ Klaus Stelter', Thomas Kühnel2 , Gero Strauß33, Jens Waschke4, \\ Thomas Kirchner ${ }^{5}$, Hans Rudolf Briner ${ }^{6}$, Daniel Simmen ${ }^{6}$, Marco Caversaccio ${ }^{7}$, \\ Peter John Wormald ${ }^{8}$, Nick Jones ${ }^{9}$, Andreas Leunig ${ }^{1,10}$ \\ Rhinology 50: 246-254, 2012 \\ DOI:10.4193/Rhino11.266 \\ *Received for publication: \\ December 20, 2011 \\ Department of Otorhinolaryngology, Head and Neck Surgery, Ludwig Maximilian University Munich, Germany \\ Accepted: May 19, 2012 \\ Department of Otorhinolaryngology, Head and Neck Surgery, University of Regensburg, Germany \\ Department of Otorhinolaryngology, Head and Neck Surgery, University of Leipzig, Germany \\ ${ }^{\S}$ TB and CSB contributed equally \\ Institute of Anatomy, Ludwig Maximilian University Munich, Germany \\ to this work. \\ Institute of Pathology, Ludwig Maximilian University Munich, Germany \\ Centre for Otology, Skull Base Surgery, Rhinology and Facial Plastic Surgery, The Hirslanden Clinic, Zurich, Switzerland \\ Department of Otorhinolaryngology, Head and Neck Surgery, University Hospital Bern, Switzerland \\ Department of Surgery - Otorhinolaryngology, Head and Neck Surgery, University of Adelaide, Australia \\ Department of Otorhinolaryngology, Head and Neck Surgery, University of Nottingham, United Kingdom \\ Center for Rhinology, Starnberg/Munich, Germany
}

\section{Summary}

Background: The aim of this multicentre study was to systematically analyse the strengths and weaknesses in the surgical training for endoscopic sinus surgery (ESS) and identify measures that may improve training.

Methodology: Using a structured questionnaire, 133 participants of ESS courses in seven centres in Germany, Switzerland and Australia were asked about their experiences during their dissection courses and how they perceived their course could be improved.

Results: Gaining confidence in handling of instruments and endoscopes was only a problem for participants with little experience in ESS. The majority of the participants, independent from their level of training, considered infundibulotomy and anterior ethmoidectomy as the easiest dissection steps, whilst surgery of the frontal sinus posed a considerable challenge for many surgeons even those with a higher level of training. Participants with and without ESS experience thought that emphasis on anatomy was the most important improvement that could be made during their surgical training. Virtually all participants stated that the course improved their anatomical knowledge, their surgical skills and their confidence when performing ESS.

Conclusions: ESS dissection courses are considered beneficial by surgical trainees. Participants felt that more emphasis on sinus anatomy in conjunction with private study is essential to maximize their skills in surgical dissection. For beginners with ESS, an infundibulotomy and anterior ethmoidectomy were thought to be the best initial procedures to help develop endoscopic surgical skills.

Key words: FESS, ESS, endoscopic sinus surgery, training, dissection course, evaluation 


\section{Introduction}

Training courses for endoscopic sinus surgery (ESS) are now an established part of otolaryngology head and neck surgical training ${ }^{(1)}$. Most courses start with theory and are followed by hands-on training on cadavers. McFerran et al., conducted a study in England which showed that about 50 percent of surgeons start performing their own ESS without having attended a training course beforehand ${ }^{(2)}$. When questioned, the majority of these surgeons wished they had done a dissection course beforehand. Zuckermann et al., demonstrated that cadaveric sinus dissection improves both subjective and objective surgical skills ${ }^{(3)}$. Surgical skills are important in ESS not only because of the difficulty in manipulating endoscopes and instruments but also because of the complex and variable anatomy and the risk of causing a significant complication. With proper training, cadaver dissection courses, and supervision, it is considered safe for surgical trainees to perform ESS on patients ${ }^{(4,5)}$. Although ESS courses are important for training there have been no studies analyzing the specific problems surgical trainees encounter in ESS and ESS training courses ${ }^{(6)}$. This study was performed to evaluate the experiences and problems in a multicentre study conducted in seven centres around the world.

\section{Materials and methods}

One hundred and thirty three participants of ESS courses in Germany (Munich, Regensburg, Leipzig, Starnberg), Switzerland (Zurich, Bern) and Australia (Adelaide) received a standardized questionnaire, which included questions about their level of surgical training, problems encountered during specific steps of the dissection and suggestions on how the training could be improved (Figure 1). All 7 courses took place in 2010 and 2011, were of several days' duration (median: three days) and included didactic lectures with multimedia presentations about basic and advanced ESS, live operations and a hands-on supervised cadaver dissection. The surgical steps demonstrated and performed by demonstrators included nasal endoscopy, infundibulotomy and middle meatal antrostomy, anterior and posterior ethmoidectomy, sphenoidotomy, surgery of the frontal sinus and recess, identification of the sphenopalatine and anterior ethmoidal artery, orbital decompression and canthotomy, transnasal dacryocystorhinostomy, transnasal closure of CSF leaks as well as approaches to the pterygopalatine fossa, sella and clivus.

\section{Statistical analysis}

Statistics were computed by SPSS Statistics 17.0 (SPPS Inc., Chicago, IL, USA).

\section{Results}

Participants

One hundred and thirty three participants from seven centres returned valid questionnaires. The analyses were done by authors blinded to the origin of the questionnaires. The questionnaires were sorted according to the number of participants (Table 1). In total, 93 participants were male (67\%), and 40 were female (30\%). The mean age of the participants was 36 years (median 34 years, range 26 - 56 years). Participants had a mean ENT experience of 7.5 years (median 5 years, range 1 - 27 years). Only 9 participants (7\%) stated that they were lefthanded, while the rest (93\%) was right-handed. In total, $38 \%$ of participants had never performed ESS before, $20 \%$ had some ESS experience ( $\leq 10$ ESS performed), while $41 \%$ had performed $>10$ ESS (Table 1) and 37\% of the surgeons had performed microscopic guided surgical operations (with numbers given between 1 and 2000).

\section{Motivation for participating in the course}

All participants were asked about their motivation for participating in the ESS course (multiple answers were allowed). Ninety five percent had attended the course to improve their surgical skills or preparing for and performing ESS whilst 13\% cited preparation for the ENT specialist exam. The acquisition of CME points was only relevant for $5 \%$. A single participant stated improving their competence in postoperative care as motivation for attending the course.

\section{Problems with instruments}

Twenty-nine participants (22\%) stated that they had experienced problems with instrumentation in the course, and 11 ascribed this to a lack of experience. In this group 3 had no previous ESS experience, while 8 had at least some ESS experience (between 0 and 10 operations, cf. Table 2). For 2 participants (one with 0 , the other with $\leq 10$ ESS performed), the names of the instruments were stated as problematic. Eighteen participants held the course organizers responsible for their problems with instruments, 12 complained about a limited selection of instruments, and 6 about the quality of instruments provided (not sharp enough). In one case, problems with instruments were stated without giving a reason.

Problems with endoscopes

Twenty-eight participants (21\%) had problems with the endoscope or camera. The most frequent problem was the handling of the endoscopes, namely the correct hand posture and using them together with instruments ( 15 participants), with 2 participants complaining about hand cramps after some time. One participant was constantly hampered by the cables attached to the instruments. A common problem was recognizing the orientation of the image with angled endoscopes $\left(30^{\circ}, 45^{\circ}\right.$ and $\left.70^{\circ}\right)$, in 11 cases. A single participant had problems with the $0^{\circ}$ endoscope and 5 participants had trouble getting a clear picture with the camera. 


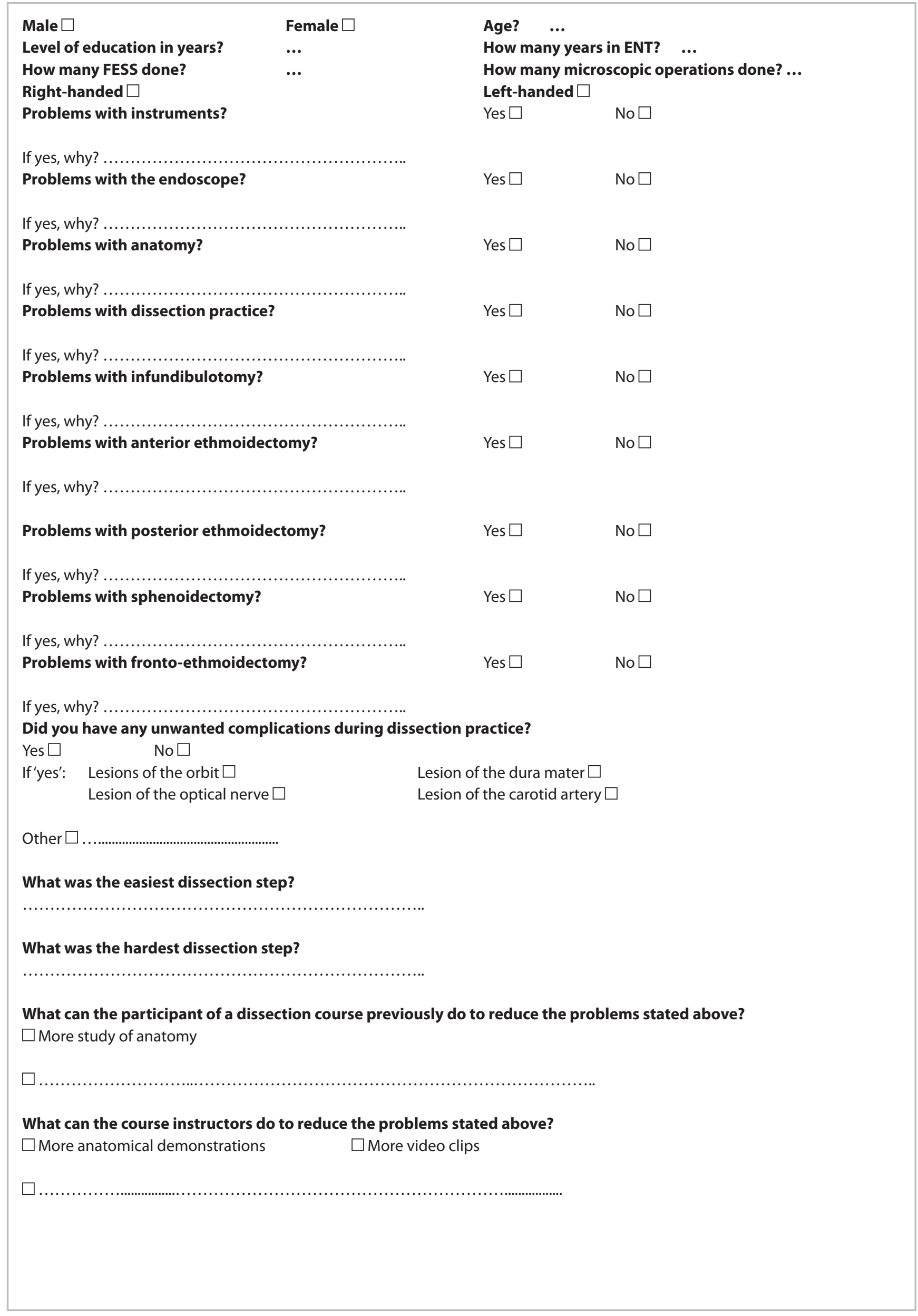


What is the best way to gain a profound anatomical knowledge about the paranasal sinuses in your opinion?
$\square$ Anatomical atlas
$\square$ Anatomical textbook
$\square$ Anatomical video animations
$\square$ General ENT textbook $\square$ Textbook of ENT surgery
$\square$ Surgical videos
$\square$ Assisting a FESS surgeon $\square$ Dissection course
$\square$ Interactive learning program

$\square$

\section{Did you respect anatomical landmarks during dissection?}

Yes $\square \quad$ No $\square$

If no, why?

Are you satisfied with the course?

Would you recommend the course?

$\begin{array}{ll}\text { Yes } \square & \text { No } \square \\ \text { Yes } \square & \text { No } \square \\ \ldots & \\ \ldots & \end{array}$

Which grade ( 1 = best, $6=$ worse) would you give the whole course?

Which grade ( $1=$ best, $6=$ worse) would you give the dissection practice?

What did you like about the course?

What did you not like about the course?

Which topics would you have wanted to be treated in the course additionally?

Which topics could have been relinquished?

What was your motivation in participating?

Improvement of surgical skills $\square \quad$ To get CME points $\square$

To prepare for the ENT specialist exam $\square$

Have your expectations in the course been fulfilled?

Did the course improve your anatomical skills?

Did the course improve your surgical skills?

Did the course give you more safety on the patient?

$\begin{array}{lll}\text { Yes } \square & \text { No } \square & \text { Partially } \square \\ \text { Yes } \square & \text { No } \square & \\ \text { Yes } \square & \text { No } \square \\ \text { Yes } \square & \text { No } \square\end{array}$

Other comments?

Figure 1. Standardized questionnaire used in this multicentre evaluation. 
Problems with anatomy

Twenty-one participants (16\%) had problems with the anatomy of the paranasal sinuses. Nine of these participants had no ESS experience (18\%), while 12 (15\%) had at least some ESS experience (Table 2). The main problems were translating textbook or computer tomography images into three-dimensional reality in surgery and the complex anatomy of the frontal recess.

\section{Problems with dissection practice}

Ninety eight percent of the participants stated that they had identified key landmarks during dissection. The 3 participants who did not identify landmarks during dissection did so for lack of experience in 2 cases, while in one case a septal deviation was held responsible. Twenty participants (15\%) stated that they had problems with the dissection exercises that they needed to perform. The main reasons were a lack of time ( 9 cases), poor quality of the cadaver specimen previously operated, no frontal sinus, too brittle material (8 cases). Two participants complained about general problems with dissection due to their lack of experience. In one case, no reason was given. Only 7 participants (5\%) had problems doing an infundibulotomy and middle meatal antrostomy (Table 3). Problems included the exact localization for the initial cut for an uncinectomy (3 cases), uncertainty about completeness of the dissection ( 2 cases), problems with hard bone of the cadaver (1 case), and a not specified anatomical variation in the cadaver (1 case). Anterior ethmoidectomy was only considered a problem for 6 participants (5\%, Table 3). Problems were uncertainty as when to stop with the dissection, especially when identifying the ground lamella of the middle turbinate (4 cases), too firm bone of the cadaver ( 1 case), while one participant did not specify their problem.

In contrast to doing an infundibulotomy and anterior ethmoidectomy, a posterior ethmoidectomy was a problem for 33 participants (25\%, Table 3 ). In virtually all cases, the problem was the difficult spatial orientation due to insufficient knowledge of the complex anatomy, and due to identifying landmarks and the borders of dissection. Problems doing a posterior ethmoidectomy were subjectively increased by a lack of experience and fear of causing a skull base defect. One participant said his problems with dissection were due to the firm bone of the cadaver.

Twenty-four participants (18\%) reported a problem doing a sphenoidotomy (Table 3). Most reported general insecurity, caused by a lack of anatomical knowledge and fear of causing a skull base lesion (13 cases). Five participants had problems locating the sphenoid ostium. Three were unsettled by finding anatomical variations (Onodi cells). One participant said firm bone was a problem.

Frontal sinus dissection was a problem for 42 participants (32\%, Table 3). The main problem was reported as finding the ostium of the frontal sinus due to problems with orientation in the complex anatomy of the frontal recess (14 cases). Eight participants said they were insecure with frontal sinus surgery and 7 thought their main problem was the use of unfamiliar angled optics. Four participants attributed their problems with frontal sinus dissection to unexpected anatomical variations (eg. Kuhn cells or lack of a pneumatized frontal sinus). Again, one participant complained of firm bone.

When asked about the easiest step in the dissection, most participants from all experience levels named infundibulotomy, middle meatal antrostomy, followed by anterior ethmoidectomy (Table 4). The majority considered frontal sinus surgery (especially the Lothrop procedure) as the hardest step (Table 4).

\section{Complications occurring during dissection}

Twenty-seven participants (20\%) reported that they had an unwanted complication during dissection (Table 5). There were 18 cases of an orbital complication, 4 dural lacerations, 3 avulsions of the middle turbinate, 1 nasolacrimal duct laceration, 1 tear of the optic nerve, 1 transsection of the anterior ethmoid artery, and 1 accidental opening of the cavernous sinus. A chisquare analysis did not show significant differences depending on the level of experience ( $x 2=7.073, p>0.05)$.

\section{Suggestions for improving ESS training}

When asked about what the course participant could do to reduce the problems encountered, $70 \%$ said that a more extensive private study of anatomy would have been very helpful. Few participants mentioned attending other ESS courses, operating on patients or cadavers, $10 \%)$, practicing with the endoscope (7\%), assisting in the operating room (2\%), watching ESS video clips (2\%), studying surgical textbooks (2\%) or textbooks with computer tomography images of the sinuses (1\%).

The most frequent suggestions to reduce problems during dissection were more extensive anatomical demonstrations (33\%) and more video clips with labeling of anatomical landmarks (20\%). A minor percentage of the participants wished they had received better supervision (11\%) or more time $(11 \%)$ during dissection. Only one participant would have liked to have more supervised practice with endoscopes.

Participants were also asked what they considered the best way of gaining a profound anatomical knowledge about the paranasal sinuses (Table 6). Most participants (66\%) considered ESS dissection courses as the primary way to obtain and improve their anatomical knowledge. Assisting ESS surgeons as well as watching ESS clips and reading anatomical textbooks were regarded as very helpful as well.

\section{Satisfaction with and subjective benefit from ESS training courses}

Table 7 shows a high level of satisfaction and subjective benefit from the ESS training courses for all participants. Virtually 
Table 1. Overview of sex, ENT and ESS experience of the 133 participants of the seven centres.

\begin{tabular}{|c|c|c|c|c|c|c|c|}
\hline Centre & $\begin{array}{l}\text { Number of } \\
\text { participants }\end{array}$ & Male [\%] & Female [\%] & $\begin{array}{c}\text { Median ENT } \\
\text { experience } \\
\text { [years] }\end{array}$ & $\begin{array}{l}\text { No ESS per- } \\
\text { formed [\%] }\end{array}$ & $\begin{array}{l}\leq 10 \text { ESS per- } \\
\text { formed [\%] }\end{array}$ & $\begin{array}{l}>10 \text { ESS per- } \\
\text { formed [\%] }\end{array}$ \\
\hline 1 & 30 & 90 & 10 & 6 & 23 & 7 & 70 \\
\hline 2 & 27 & 63 & 37 & 6 & 41 & 30 & 30 \\
\hline 3 & 25 & 72 & 28 & 4 & 52 & 28 & 20 \\
\hline 4 & 18 & 56 & 44 & 10.5 & 61 & 17 & 22 \\
\hline 5 & 17 & 53 & 47 & 4 & 41 & 29 & 29 \\
\hline 6 & 12 & 67 & 33 & 7.5 & 8 & 17 & 75 \\
\hline 7 & 4 & 100 & 0 & 7.5 & 25 & 0.0 & 75 \\
\hline Total & 133 & 70 & 30 & 7.5 & 38 & 20 & 41 \\
\hline
\end{tabular}

Table 2. Comparison of problems with instrument, endoscope and camera handling and anatomy occurring during dissection as reported by participants with different levels of ESS experience.

Problems with...

Instrument handling

Endoscope and camera handling

Anatomy
No ESS experience [\%]

$\leq 10$ ESS performed [\%]

$>10$ ESS performed [\%]

6
8
18

19

67

19

13

13

Table 3. Comparison of problems with dissection areas as reported by participants with different levels of ESS experience.

\begin{tabular}{lcccc}
\multicolumn{1}{c}{ Problems with ... } & No ESS experience [\%] & $\leq 10$ ESS performed [\%] & > 10 ESS performed [\%] \\
\hline $\begin{array}{l}\text { Infundibulotomy and middle } \\
\text { meatal antrostomy }\end{array}$ & 4 & 7 & 6 \\
Anterior ethmoidectomy & 4 & 7 & 4 \\
\hline Posterior ethmoidectomy & 33 & 30 & 15 \\
\hline Sphenoidotomy & 9 & 19 & 13 \\
Frontal sinus & 43 & 44 & 15
\end{tabular}

all participants reported satisfaction with their course, an improvement in their anatomical knowledge, surgical skills and confidence with the ability to operate. With minor differences, all centres received excellent grades, with a mean rating of all centres of 1.4 (range 1 to 6 , with 1 as best).

\section{Discussion}

Participants of the present multicentre study were mostly young colleagues with a median ENT experience of 5 years. The authors wanted to know which problems arise in different levels of surgical experience and therefore participants were separated into three groups with no, some or more ESS experience based on the number of operations performed. There is no data about the exact learning curve of ESS surgeons but we arbitrarily chose 10 operations as the limit between some and more experience.

The most relevant motivating factor for attending ESS courses is the aim to improve surgical skills, whilst preparation for the ENT specialist exam was secondary to this. Therefore organizers of FESS course should focus on good dissection practice (with adequate cadavers, instruments and supervision) to fulfill their participants' expectations. The acquisition of CME points is a less significant factor, as shown by previous studies ${ }^{(1,6)}$.

The literature reports a high level of satisfaction with a high 


\section{Easiest dissection step}

\begin{tabular}{|c|c|c|c|}
\hline $\begin{array}{l}\text { Infundibulotomy and middle } \\
\text { meatal antrostomy }\end{array}$ & 74 & 63 & 53 \\
\hline Anterior ethmoidectomy & 24 & 15 & 20 \\
\hline Posterior ethmoidectomy & - & - & - \\
\hline Sphenoidotomy & 4 & 4 & 6 \\
\hline Frontal sinus & - & - & - \\
\hline Other & 8 & 5 & 16 \\
\hline \multicolumn{4}{|l|}{ Hardest dissection step } \\
\hline $\begin{array}{l}\text { Infundibulotomy and middle } \\
\text { meatal antrostomy }\end{array}$ & 4 & 4 & 2 \\
\hline Anterior ethmoidectomy & 4 & 4 & 4 \\
\hline Posterior ethmoidectomy & 8 & 7 & 7 \\
\hline Sphenoidotomy & 14 & 11 & 10 \\
\hline Frontal sinus & 67 & 37 & 53 \\
\hline Other & 8 & 26 & 24 \\
\hline
\end{tabular}

Table 4. Easiest and hardest dissection steps as reported by participants with different levels of ESS experience.

subjective benefit from dissection courses ${ }^{(1)}$. Not only were nearly all participants of the seven centres satisfied with their course and would recommend the course to colleagues, but also nearly all participants attributed improved anatomical knowledge, surgical skills and confidence to the course.

Bakker et al., reported that in ESS training, manual skills are more easily achieved than spatial orientation (7). Table 2 shows that in the groups who had done $\leq 10$ or $>10$ ESS the percentage of participants who reported that they had problems with the anatomy or spatial orientation did not decrease with experience. Interestingly, participants with no ESS experience reported fewer problems with instrument and endoscope handling than participants who had previously performed a small number of ESS $(\leq 10)$. An explanation could be that surgeons without any FESS experience focus on actually performing the necessary dissection steps and do not perceive faulty handling of instruments or endoscopes to the same degree. In the group of more experienced surgeon's problems with instruments and endoscopes was no longer a problem.

A minority of participants complained about a lack of time or a brittle cadaver. Some participants in all centres reported this and it is likely that it was due to individual variations in the preservation of the cadavers.

Independent of the level of experience, infundibulotomy and anterior ethmoidectomy were considered the easiest dissection steps. These should therefore be selected as the first operations to be performed on patients. The hardest dissection steps were posterior ethmoidectomy and frontal sinus surgery (Table 4), but with a learning curve that improved with experience (Table 3). The main reason for problems with these areas of dissection were a lack of spatial orientation during dissection caused by a poor understanding of the complex anatomy. Table 6 shows the preferred way ESS course participants gained anatomical knowledge about the paranasal sinuses. The dissection courses themselves were considered to be the best way to increase anatomical knowledge.

Complications during dissection were more frequent by trend in the group of participants with little experience ( $\leq 10$ ESS) (Table 5). An explanation for a lower complication rate in participants with no experience compared to participants with little experience could be that these participants did less extensive surgery, and that participants of the second group were more likely to explore the limits of the dissection. However, statistical analysis did not show significant differences, maybe due to the limited number of unwanted complications in total. Furthermore, the data in this paper was a subjective assessment and was not validated by assessing participant's performance. Further research to document objective improvements in skill levels from specific teaching modules would be valuable.

\section{Conclusion}

ESS dissection courses are well accepted and considered to be beneficial by surgical trainees. Exhaustive private study of anatomy is essential to maximize the benefit of dissection courses. 
Table 5. Comparison of complication rates during dissection as reported by participants with different levels of ESS experience (for details, see text).

\section{No ESS experience [\%]}

Complication rate
14
$>10$ ESS performed [\%]

Table 6. Preferred options of ESS course participants how to gain anatomical knowledge about the paranasal sinuses (naming of multiple options allowed).

\begin{tabular}{ll}
\hline ESS dissection course & 66 \\
\hline Assisting ESS surgeons & 47 \\
\hline Surgical video clips & 32 \\
Anatomical atlas & 30 \\
\hline Anatomical video clips demonstrating 3D anatomy & 21 \\
Surgical textbook & 20 \\
\hline Anatomical textbook & 15 \\
Interactive learning program & 14 \\
\hline ENT textbook & 9
\end{tabular}

Table 7. Satisfaction with and subjective benefit from the ESS training courses as stated by all participants ( $n=133, n$. a. $=$ not applicable).

\begin{tabular}{|c|c|c|c|c|}
\hline & Yes [\%] & No [\%] & Partially [\%] & No statement [\%] \\
\hline $\begin{array}{l}\text { I am satisfied with the } \\
\text { course }\end{array}$ & 99 & 0 & n. a. & 2 \\
\hline $\begin{array}{l}\text { I would recommend the } \\
\text { course to my colleagues }\end{array}$ & 99 & 0 & n. a. & 2 \\
\hline $\begin{array}{l}\text { My expectations concern- } \\
\text { ing the course have been } \\
\text { fulfilled }\end{array}$ & 90 & 0 & 9 & 2 \\
\hline $\begin{array}{l}\text { My anatomical knowledge } \\
\text { has improved }\end{array}$ & 97 & 2 & n. a. & 2 \\
\hline $\begin{array}{l}\text { My surgical skills have } \\
\text { improved }\end{array}$ & 96 & 3 & n. a. & 2 \\
\hline $\begin{array}{l}\text { My confidence with the } \\
\text { patient has improved }\end{array}$ & 95 & 4 & n. a. & 2 \\
\hline
\end{tabular}

\section{Acknowledgements}

This work received no funding.

\section{Authorship contribution}

TB, CSB, AL: Concept and idea, manuscript preparation in cooperation with the other authors.

\section{Conflict of interest}

No conflict of interests. 


\section{References}

1. Gurr A, Hansen S, Minovi A, Probst G, Dazert $\mathrm{S}$. The relevance of anatomical courses in ENT education. Laryngo-Rhino-Otol. 2009; 88: 789-792.

2. McFerran DJ, Grant HR, Ingrams DR, Fife DG. Endoscopic sinus surgery: are junior doctors being properly trained? Ann R Coll Surg Engl. 1998; 80: 359-363.

3. Zuckerman JD, Wise SK, Rogers GA, Senior BA, Schlosser RJ, DelGaudio JM. The utility of cadaver dissection in endoscopic sinus surgery training courses. Am J Rhinol Allergy 2009; 23: 218-224.

4. Kinsella JB, Calhoun $\mathrm{KH}$, Bradfield JJ, Hokanson JA, Bailey BJ. Complications of endoscopic sinus surgery in a residency training program. Laryngoscope 1995; 105: 1029-1032
5. Nguyen QA, Cua DJ, Ng M, Rice DH. Safety of endoscopic sinus surgery in a residency training program. Ear Nose Throat J. 1999; 78: 898-902, 904.

6. Braun T, Betz CS, Stelter K, Leunig A. FESS and surgical training: what are the problems? Laryngo-Rhino-Otol. 2011; 90: 10-14.

7. Bakker NH, Fokkens WJ, Grimbergen CA. Investigation of training needs for functional endoscopic sinus surgery (FESS). Rhinology 2005; 43: 104-108.
Dr. med. Thomas Braun

Klinik und Poliklinik für Hals-Nasen-

Ohrenheilkunde

der Ludwig-Maximilians-Universität München

Marchioninistraße 15

D-81377 München

Germany

Tel: +49-89-70950

Fax: +49-89-7095 6869

E-mail: thomas.braun@med.unimuenchen.de

\section{0th INTERNATIONAL COURSE IN ADVANCED SINUS SURGERY TECHNIQUES}

Dissection course with fresh frozen cadaver heads

Teacher of Honour: Prof. Richard J Harvey

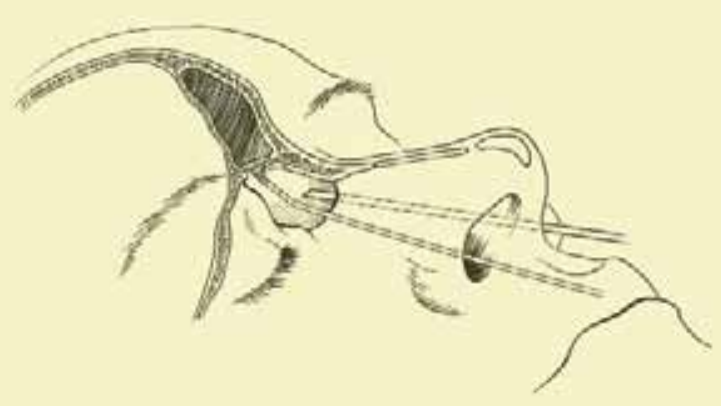

March 7-8, 2013

Department of Otorhinolaryngology Academic Medical Center of the University of Amsterdam The Netherlands

For further information contact Wytske J. Fokkens, MD, PhD ENT dept. AMC Course Secretariat Tel: 0031205668586 / Fax 0031205669573 Email:m.b.vanhuiden@amc.uva.nl 